\title{
Research on the Development Trend of Higher Education Reform in China
}

\author{
Yu Bai ${ }^{1,2}$ \\ ${ }^{1}$ College of Literature \\ Yan'an University \\ Yan'an, China \\ ${ }^{2}$ School of Liberal Art \\ Renmin University of China \\ Beijing, China
}

\begin{abstract}
By using the method of literature, comparative analysis, etc., the paper mainly discussed the trends of Chinese higher education reform. The results show that the reform of higher education in China conforms to the need of social change, is the concrete embodiment of the social development and changes, and higher education reform in China from the market economy, students' double identity, the quality of higher education and supervision and evaluation system are the trends of higher education reform in China. The conclusions are that breaking the monopoly of the government economy, making full use of the role of the students, developing and implementing effective supervision is the key to achieve success.
\end{abstract}

Keywords-Chinese higher education; reform; future; development; trend

\section{INTRODUCTION}

In Chinese traditional mind, stability is all. If there is a change, people are in a panic. But social development is the normality, immutability is very abnormal. China's higher education is moving forward in constant changes, the first large-scale reform is the recruitment of students in colleges and universities.

From the college enrollment plan had been restored to 1997, the country has three major enrollment modes: the national entrance examination, entrusted training and selffinanced project, and tuition fees were different. Then reforms have begun from 1997, the state adopted the merger of enrollment system, and enrolled more students who should pay for tuition by themselves. As a result, the standard of admission scores and tuition are unified, and the change was considered to be a big event in the development of higher education in China. Now China's higher education is brewing a new round of reform, and the new reform is considered to be another self-transformation. Interestingly, what are the tendencies of the new reform? So, the article will discuss something from three aspects.

\section{ThE NECESSity OF HigheR EdUCATION REFORM}

\section{A. The need of social development}

The development of society cannot be separated from the training of all kinds of talents. Social culture, economy, politics, sports and other needs the talents, needs the joint efforts of all kinds of talents, and the cradle of cultivating all kinds of talents at all levels of colleges and universities is not. However, in the more than 2 thousand universities, there is a serious phenomenon of overlap, which is not only reflected in the disciplines and professional settings, but also exists in the training objectives, training quality. This phenomenon has led to the cultivation of talents in Colleges and universities are not rich enough, the quality of personnel is uneven, and it is difficult to adapt to the rapidly changing social needs. Therefore, it is a necessary way to adjust the talent training goal, to create a new type of specialty and to improve the quality of talent training.

\section{B. The need of personal development}

The functions of higher education including personnel training, scientific research and social service determine higher education must continue to reform and develop in order to meet the needs of the state, society and individuals for higher education. But China's higher education is regarded as an important part of the national superstructure, fully obey, serve the country's political and economic needs, and the individual and even the needs of the community are often ignored.

With the development of the pluralistic society, the appearance of education is the diversification of the demand for individual education, and the diversification of the demand comes from the difference of individual subjectivity and personal preference. Because of people's physical and mental development, full development to achieve the all-round development of people and individual potential, education should follow the laws of physical and mental development, through good education, promoting education to a higher level of development. This is not only the purpose of education is to meet the individual needs of education. The individual development needs to be used as an internal standard for the 
development of higher education reform, and the social need to be unified in the full development of human and individual potential.

\section{THE TENDENCY OF ChinA’s Higher EDUCATION REFORM}

\section{A. The market tendency}

Higher education reform in China will continue to follow the path of market economy, and strive to be in line with international higher education reform. Since the merger of enrollment, colleges and universities are divided into 985, 211 and other different grades, the employment market began to exist popular and unpopular majors, all these made significant differences in graduated students' wage level and welfare, obviously, market economy in development of higher education in China is a dark proposition that cannot be ignored, and it will be an important tendency of the development of higher education in China.

In March 2014, Chinese revolutionized its higher education, "in 1999 more than 600 colleges which were upgraded from junior college to senior college since 1999 would be gradually transited into Career Technical College, focusing on the training of engineers, senior technicians and highly qualified workers, etc. The breakthrough of the education reform is system of modern occupation education, and the purpose is to develop the skills and talents, and to coordinate the contradiction between the employment of college graduates and the lack of technical skills needed in market. [1]

Obviously, the trend of higher education reform lies in demand of the market. Not only the personnel training should be based on market demand, but also the value of talents according to the market and the education, tuition is no longer simple across the board, but according to the different professional to calculate tuition expenses fairly and reasonably. Followed by college students' education loan mechanism will become more perfect, such as the United Kingdom, students do not need to pay their tuition fees in advance, but repay the loan by installments in the case of repayment capacity after graduation, and the cut-off point was 15000 pounds, so those whose income under 15000 pounds do not need to repay the loan. The stone of the mountain can work jade.

Therefore, Higher education in China will get along with the method to develop itself, and market tendency will guide higher education development to a good direction. In the choice of market, universities want every student to get a good job, universities will try their best to improve the quality of personnel training, let students obtain valuable education, let students become high quality talents in the society, Let the students become the high quality talent to enter the society, can become the senior personnel of the society and can become the school card.

\section{B. The dual identity trend}

College students will not only play the role of the educated, but bear the dual identity of higher education, that is, the higher education of college students is not only the knowledge of higher education, but also the consumption of higher education.

This reform has been introduced in the UK. In 2011, the British public release of the reform of higher education in the new white paper, the white paper emphasizes the market position is in the center of higher education, the pure educated student's identity plus a layer as consumer education students. "The Cameron administration's higher education white paper reflects such a change, and confirms that the student is the consumer of higher education resources, who benefit, who pay." [2] Higher education institutions are becoming more and more like a "hybrid" [3].

Since it is the consumer of educational knowledge, the education needs to be educated according to the needs of consumers and the appropriate reform of the educational system. In the UK, for example, higher education recipients are more complex, in order to meet the needs of the reality of the subject of education, there are now more than 1600 educational institutions, including public and private, about 250 of them are Continuing Education College. [4] The subject of education have enough opportunities to choose desired professional according to their own situation, this is the model of higher education is also a manifestation of pluralism. The British higher education market is flexible, full of vitality; also universities and colleges in British are becoming a perfect system, and have certain competitiveness, each school for students in the most suitable design mode of education.

Different Compared with the British university complex studies, China does not has this pluralistic education mode, only full-time undergraduate education can obtain employment market acceptance, continuing education or adult education is generally not social identity. But with the development of society, employers pay more and more attention to the professional level of employees, students will be gradually extended to the general population, higher education has become a necessary part of life, the university will develop different education models according to the demands.

\section{The pursuit of the quality trend}

Quality is the foothold of the future reform of higher education. The results of the reform of higher education in all countries indicate that the popularization is a major direction of the reform of higher education.

Higher education or higher education resources are no longer solely for the elite group, so that a small number of citizens' income, the future of higher education development is the popularization of higher education development direction of the civilian population. Civilian education direction does not mean that the quality will decline, but to ensure that the public acceptance of education at the same time, so that the public's professional quality will be promoted. Higher quality is the bottom line of the reform of higher education, which is the foothold of the reform of higher education. 
At the same time, the goal of higher education personnel training is the best integration of "man" and "talent", It is not only to have the "man" of the temperature but also have "special" talent, therefore, to leave the training of personnel to talk about the reform of higher education is no sense of things.

However, since the expansion, the quality of personnel training has not been well protected. In four years of study, many college students' accumulation of professional knowledge is weak, their professional literacy is not effectively improved, and their professional system is not established.

A survey on the quality of "after 90s college students" showed that more than half of the "after 90s students" admitted contemporary college students lacked of morality, such as cheating, no credit; $39.5 \%$ of students admitted that there were often some uncivilized or disciplinary phenomenon in the students around, such as the waste of food, littering, loud noises and other public places. However, when asked what good faith is, $62.6 \%$ of the "after $90 \mathrm{~s}$ " agreed with the mainstream ideology of the moral concept, that is, honesty, thrift is the basic criteria of a man do things. But in fact, their actual action was not consistent with the understanding of these. [5] So how to change the status quo? So as to enable college students can get the forefront of education, can enjoy the value of College education.

In my opinion, we should proceed from the four aspects: First, a good environment for growth. Includes the beautiful campus environment and campus culture; second, high quality university classroom. Let each class have academic quality; third, high level university professor. Implement faculty tenure, encourage professors to go into the undergraduate class more and open the direction of professional guidance class; fourth, effective transfer of knowledge. Teachers should have a strong ability to impart knowledge, and tie the field to impart professional knowledge. What we need to pay attention to being that, a dynamic class is not necessarily a discussion of the nature of the classroom, but both the free exchange of knowledge by the spirit of vigorous vitality. This activity may be a hot debate between the two sides of the table view, as well as a resonance between teachers and students silent communication.

\section{The strict of supervision and evaluation system trend}

The perfect supervision system evaluation system is related to the success or failure of the reform of the higher education system. The criterion of testing the success or failure of the higher education reform in addition to the quality of talents, a scientific and efficient evaluation system is another important standard.

The main duty of the government is to protect the interests of students and taxpayers, and to respect and protect the university autonomy and academic freedom. [1]Entering the market is an important way to get rid of the higher education administration and bureaucracy, and the administration is no longer the killer of the academic freedom of higher education. At the same time, the governments' withdrawing from economy makes colleges have their own choice of space, government responsibilities for the development of higher education, to develop a comprehensive escort measure of higher education quality education method, strict supervision and supervision system of teaching quality, and strive to implement.

Australia's reform of the quality assurance system of higher education has been more in-depth, is considered to be a successful attempt. In 2011, Australia issued the "Higher Education Quality and Standards Department Act". The Act provides for the basic principles of higher education quality; standardize the registration of higher education institutions from the registration process, registration conditions, registration and classification, etc.; Standardize how to make higher education quality assessment standards and carry out assessment and audit work according to the standards; clarify the obligations of the higher education institutions and related personnel to assess the information, to assess the rights and obligations of experts and staff; specify how to punish the institutions of higher education according to the evaluation results; the establishment, composition, function, right and work content of the quality of higher education and Standards Department; introduces the establishment, composition, function, rights and work contents of higher education quality and standard department, as well as the composition, function and authority of the higher education quality standard. [6]

Over the past ten years, the Chinese government is trying to absorb the useful experience of foreign countries to promote the reform of higher education, carrying out the management system and evaluation system from the macro to the micro level, and it will make a comprehensive assessment of the University in China every ten years. However, this assessment is lack of effectiveness, and no continuity to solve the problems existing in University, instead to bring some great pressure for various colleges and universities. Meanwhile, problems such as how to supervise the colleges and universities, how to pay attention to the differences between different levels of college, how to improve the quality of the assessment of backward universities are not resolved in the supervision. So, the function of supervision is to find the problem to solve the problem, not to avoid the problem. Therefore, in the future reform of higher education system, the assessment of regulatory mechanisms needs to be further improved, need to play its practical role.

\section{CONCLUSION}

To some extent, the reform process is the test process, filled with failure and success. In the reform road of higher education in the future, we should draw on collective wisdom and absorb all useful ideas, uphold the minimum education line. In the process of considering the fine points of the development model of higher education, the reform of higher education system in our country must be slow.

\section{REFERENCES}

[1] Jun Gu. "600 colleges turn to Vocational education", can colleges convert successfully? [J]. Shaanxi Education: Comprehensive, 2014 (5): 28-30.(In Chinese) 
[2] Jianbing Dai, Renyao Zhong. A new trend of higher education reform in UK: market centered [J]. Modern University Education, 2012 (4): 51-53. (In Chinese)

[3] Shengbing Li. Marketization of Higher Education: A study on the European perspective [J]. Higher Education, 2000 (4): 109. (In Chinese)

[4] Great Britain Department for Business' Innovation \& Skills( BIS). Higher Education: Students at the Heart of the System [R/OL].
London: The Stationery Office. June 2011 [2012-04-16] . http: //c561635. r35. cf2.rackcdn.com/11 - 944-WP-students-at-heart.pdf.

[5] Jia Yu. Investigation and analysis on the current situation of quality education in college students after 90s [J]. School Party Building and Ideological Education, 2011 (23): 36-38. (In Chinese)

[6] Attorney-General's Department, Canberra. Tertiary Education Quality and Standards Agency Act 2011[EB/OL].http://www.comlaw.gov.au./ details/C2011-07-29/2011-12-15. 